Article

\title{
Characterization, Molecular Docking, and In Vitro Dissolution Studies of Solid Dispersions of 20(S)-Protopanaxadiol
}

\author{
Qi Zhang ${ }^{1,2,+}$, Yiqiong Pu ${ }^{1, \dagger}$, Bing Wang ${ }^{1,2, *}$, Yuqin Wang ${ }^{3}$, Tina Tingxia Dong ${ }^{4}$, Tao Guo ${ }^{5}$,
} Tong Zhang ${ }^{1,2}$ and Zhenzhen Cai ${ }^{6, *}$

1 Experiment Center for Teaching and Learning, Shanghai University of Traditional Chinese Medicine, Shanghai 201203, China; zhang645654@163.com (Q.Z.); puyiq@163.com (Y.P.);

zhangtdmj@hotmail.com (T.Z.)

2 School of Pharmacy, Shanghai University of Traditional Chinese Medicine, Shanghai 201203, China

3 Zhejiang BioAsia Institute of Life Science, No.1938 Xinqun Road, Economic and Technical Development Zone, Pinghu 314200, Zhejiang, China; wyq@bioasia.com.cn

4 Division of Life Science and Center for Chinese Medicine, The Hong Kong University of Science and Technology, Hong Kong, China; botina@ust.hk

5 Center for Drug Delivery Systems, Shanghai Institute of Materia Medica, Chinese Academy of Sciences, Shanghai 201203, China; gotallcn@163.com

6 Experiment Center for Science and Technology, Shanghai University of Traditional Chinese Medicine, Shanghai 201203, China

* Correspondence: annabel_cn@163.com (B.W.); czz2021@vip.sina.com (Z.C.); Tel.: +86-21-5132-3123 (B.W.); +86-21-5132-3077 (Z.C.)

+ These authors contributed equally to this work.

Academic Editor: Anusha Chaparala

Received: 14 November 2016; Accepted: 6 February 2017; Published: 11 February 2017

\begin{abstract}
In this study, we prepared solid dispersions (SDs) of 20(S)-protopanaxadiol (PPD) using a melting-solvent method with different polymers, in order to improve the solubility and dissolution performance of drugs with poor water solubility. The SDs were characterized via differential scanning calorimetry (DSC), powder X-ray diffraction (PXRD), Fourier transform infrared spectroscopy (FTIR), nuclear magnetic resonance (NMR), and molecular docking and dynamics study. DSC and PXRD results indicated that PPD crystallinity in SDs was significantly reduced, and that the majority of PPD is amorphous. No interaction was observed between PPD and polymers on FTIR and NMR spectra. Molecular docking and dynamic calculations indicated that the PPD molecule localized to the interpolated charged surface, rather than within the amorphous polymer chain network, which might help prevent PPD crystallization, consequently enhancing the PPD dispersion in polymers. An in vitro dissolution study revealed that the SDs considerably improved the PPD dissolution performance in distilled water containing $0.35 \%$ Tween- 80 (T-80). Furthermore, among three PPD-SDs formulations, Poloxamer188 (F68) was the most effective in improving the PPD solubility and was even superior to the mixed polymers. Therefore, the SD prepared with F68 as a hydrophilic polymer carrier might be a promising strategy for improving solubility and in vitro dissolution performance. F68-based SD, containing PPD with a melting-solvent preparation method, can be used as a promising, nontoxic, quick-release, and effective intermediate for other pharmaceutical formulations, in order to achieve a more effective drug delivery.
\end{abstract}

Keywords: 20(S)-protopanaxadiol; solid dispersion; polymer; molecular docking; in vitro dissolution 


\section{Introduction}

Ginseng, the root of Panax ginseng C. A. Meyer, has been used as a medicinal plant in China for thousands of years. In modern medicine, ginseng is generally used to treat inflammation, anxiety, depression, fatigue, diabetes, and other disorders [1-5]. Ginsenosides, the main bioactive ingredients [6], can be classified according to the sapogenin structure, as follows: the panaxadiol (e.g., Rb1, Rb2, Rb3, Rc, Rd, Rg3, Rh2, and Rs1), panaxatriol (e.g., Re, Rf, Rg1, Rg2, and Rh1), and oleanolic acid groups (e.g., Ro) [7-9]. Ginsenosides exert biological effects, such as anti-inflammation, anti-anxiety, anti-hypertensive, and anti-tumor effects [8,10-13]. Many effective enzymatic preparations can be used to obtain highly purified 20(S)-protopanaxadiol (PPD, aglycon of the panaxadiol group) (Figure 1) [14-17]. Studies [18-20] have reported that PPD is the main metabolite of protopanaxadiol ginsenosides (after oral administration), and its anticancer effect has been demonstrated to be more effective than that of some ginsenosides. Furthermore, the PPD transformation from ginsenosides $\mathrm{Rb} 1, \mathrm{Rb} 2$, and Rc induced an anti-metastatic or anti-carcinogenic effect [21]. Thus, PPD is a potential therapeutic agent for treating various cancers [22-24]. Moreover, since PPD has an anti-tumor potential, and an auxiliary anti-tumor agent, the Yijinsheng Capsule (PPD is the major component) has begun late-stage clinical trials. Thus, it is necessary to improve its solubility and dissolution performance.

However, PPD is a chemical biopharmaceutics classification system (BCS) II drug with low solubility [25] (approximately $3 \mu \mathrm{g} / \mathrm{mL}$ ) and a relatively favorable oil/water partition coefficient [26] $(\log P=1.72)$. Researchers reported that this sapogenin exhibited low absolute bioavailability [27], and relative bioavailability of oral formulations (rats: 31\%; dogs: 9.6\%) [28]. Moreover, its low solubility and first-pass effects [25] led to low bioavailability, which hindered its development and therapeutic applications [29]. Therefore, the development and therapeutic use of this active agent is relatively limited.

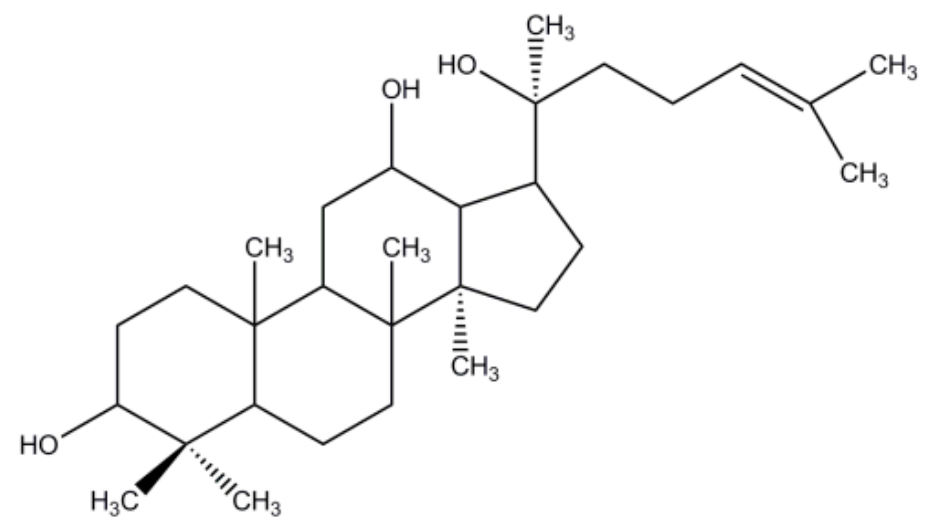

Figure 1. Chemical structure of 20(S)-protopanaxadiol (PPD).

Solid dispersion (SD), wherein one or more poorly soluble drugs are dispersed in hydrophilic polymers, is an effective method for improving the solubility and bioavailability of poorly soluble compounds [30-32]. Hydrophilic polymer properties determine drug dissolution capacities [33]. SD polymers [34-39], such as polyethylene glycol, polyvinylalcohol, cellulose derivatives, polyvinyl pyrrolidone, and poloxamer, are mostly hydrophilic. Three major SD preparation methods include melting [40], solvent [41], and melting-solvent methods [42]. The drug in SD can be dispersed as separate molecules, amorphous particles, or crystalline particles; whereas the carrier can be crystalline or amorphous [43]. Numerous studies have highlighted the advantages of SD in the improvement of the solubility and dissolution rate of drugs with poor water solubility [44-46]. For example, SD can convert drugs from a crystalline state to one which is amorphous, thereby avoiding drug recrystallization. Moreover, because of small particle size, the permeability or porosity of SD is 
relatively high $[47,48]$. Compared with other techniques for improving the bioavailability of poorly soluble drugs, such as salt formation, particle-size reduction, and solubilization (cosolvent, micelles, and emulsions), SD has several advantages. It reduces the drug particle size to molecular level; whereas other conventional particle-size reduction techniques easily cause agglomeration during formulation, dissolution, or storage $[49,50]$. Furthermore, SD can be formulated in oral solid preparations, which are more acceptable to patients than liquid products produced through solubilization [51,52]. Therefore, SD has been widely used to develop new drugs as one of the most effective formulations to improve the solubility and bioavailability of water-insoluble drugs [53,54]. Identification of drugs dispersion state in SD is essential. During this quality control process, differential scanning calorimetry (DSC), powder X-ray diffraction (PXRD), Fourier transform infrared spectroscopy (FTIR), and nuclear magnetic resonance (NMR) analyses are commonly used to characterize SD physicochemical formations. DSC and PXRD revealed drug existential states in SDs; whereas FTIR, NMR, and molecular docking calculation are usually employed to study the nature of molecular interactions between drugs and polymer systems.

Up to now, few PPD formulations have been fully developed, among which only a few have improved water solubility, such as SD, emulsions, hydroxypropyl- $\beta$-cyclodextrin inclusion, and colloidal dispersions [55-60]. In this study, SD with different polymers has been developed via melting-solvent method to optimize formulation and characterize their physicochemical formation with DSC, PXRD, FT-IR, and NMR. A molecular docking and dynamics study also explored PPD and polymer interaction. The water solubility and in vitro dissolution performance of SDs prepared with different formulations were also evaluated.

\section{Results and Discussion}

\subsection{Drug Loading Efficiency and Solubility Measurement}

The drug loading efficiency (DL) of the three SDs (F1-F3) were $8.17 \% \pm 2.93 \%, 8.13 \% \pm 2.56 \%$, and $7.91 \% \pm 0.74 \%(p>0.05$, all against all SDs), respectively. The solubility of F1, F2, and F3 were $4.66 \pm 0.93 \mu \mathrm{g} / \mathrm{mL}, 33.24 \pm 2.04 \mu \mathrm{g} / \mathrm{mL}$, and $14.33 \pm 0.86 \mu \mathrm{g} / \mathrm{mL}$, respectively. The solubility of the three formulations (F1-F3) significantly differed from each other $(p<0.05)$.

The solubility measurement results exhibited different polymer effects on the drug dissolvability increase in water. The PPD water solubility in SDs clearly increased when compared with that of pure PPD at $37^{\circ} \mathrm{C}$ (approximately $3 \mu \mathrm{g} / \mathrm{mL}$ [25]). F2 exhibited the highest solubility $(33.24 \pm 2.04 \mu \mathrm{g} / \mathrm{mL}$ ), which differed significantly from that of the other SDs $(p<0.05)$.

\subsection{Characterization}

\subsubsection{DSC Analysis}

The DSC thermograms of the drug, polymers, SDs, and Physical mixtures (PMs) are shown in Figure 2. The pure PPD exhibited an endothermic peak at $216^{\circ} \mathrm{C}$ (Figure 2A), which corresponds to its melting point. PEG6000 (Figure 2B) and F68 (Figure 2C) were detected at their respective melting points of $60^{\circ} \mathrm{C}$ and $53{ }^{\circ} \mathrm{C}$, which are the melting points of these polymers. The DSC curves of SDs (Figure 2D-F) and PMs (Figure 2G-I) were similar to those of the polymers, where there was no endothermic peak at $216^{\circ} \mathrm{C}$. PPD existed in SDs in amorphous states.

In DSC analyses, PPD and polymer characteristic peaks were expected in the DSC thermograms of PMs. However, the DSC thermograms of PMs were quite similar to those of polymers, which can be explained by relating them to the SD formation process and the ratio of PPD and polymers in the formulation. As shown in DSC thermograms, polymer melting points $\left(53^{\circ} \mathrm{C}\right.$ and $\left.60{ }^{\circ} \mathrm{C}\right)$ were much lower than that of PPD $\left(216^{\circ} \mathrm{C}\right)$, during DSC analysis, wherein each sample was heated at $10{ }^{\circ} \mathrm{C} / \mathrm{min}$ from $25{ }^{\circ} \mathrm{C}$ to $300{ }^{\circ} \mathrm{C}$. Polymers were melted when the temperature reached $53{ }^{\circ} \mathrm{C}$ (F68) or $60^{\circ} \mathrm{C}$ (PEG6000). This process was quite similar to SD formation, which indicated that melting 
PM actually existed in a state of SD. Moreover, large polymer amounts in PM (drug-polymer ratio $=1: 10$ ) had masked the existence of PPD DSC analysis, which might also lead to the disappearance of the endothermic peak of PPD in the PM thermograms [61-64]. PPD was indicated as being in an amorphous state in SDs, wherein no definite melting point of PPD was determined. This inference could also be confirmed by the PXRD analysis results. Another reason for the drug not being detected might be a lack of equipment sensitivity, as reported in [61].

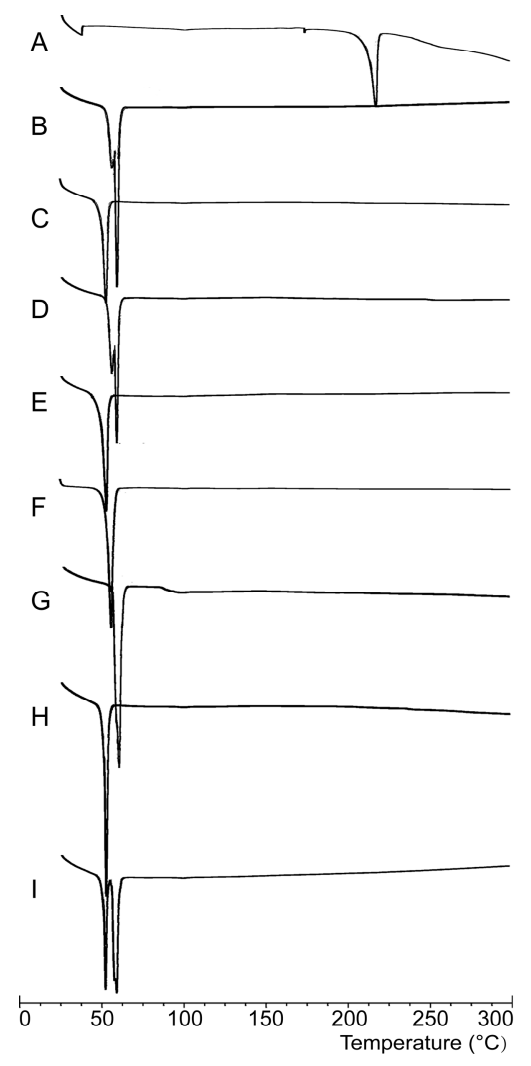

Figure 2. Differential scanning calorimetry (DSC) thermograms of PPD (A), Polyethylene glycol 6000 (PEG6000) (B), Poloxamer 188 (F68) (C), Formulation 1 (F1) (D), Formulation 2 (F2) (E), Formulation 3 (F3) (F), Physical mixture with PEG6000 (PEG6000 PM)(G), Physical mixture with F68 (F68 PM) (H), Physical mixture with PEG6000 and F68 (PEG6000 and F68 PM) (I).

\subsubsection{PXRD Analysis}

In PPD diffractograms, PPD exhibited high crystallinity, with characteristic crystalline peaks at $4.17^{\circ}, 6.59^{\circ}, 14.74^{\circ}$, and $15.68^{\circ}$ (Figure $3 \mathrm{~A}$ ), which revealed that PPD was in a crystalline state. PEG6000 (Figure 3B) had characteristic crystalline peaks at $19.34^{\circ}$ and $24.48^{\circ}$, whereas F68 (Figure 3C) had characteristic crystalline peaks at $19.25^{\circ}$ and $23.57^{\circ}$. SD diffractograms (Figure 3D-F) exhibited characteristic crystalline peaks of the corresponding polymer and some characteristic peak signals of PPD in different degrees of amorphization. F1 and F2 exhibited completely amorphous characters in the absence of PPD characteristic peaks, which indicated that the majority of PPD in these SDs (F1 and F2) presented in the amorphous state (Figure 3D-E). However, some PPD diffraction peaks could be observed in F3 (Figure 3F), which suggested that the majority of PPD in F3 existed in an amorphous state, and only a small amount existed in a crystalline state. PM diffractograms (Figure 4G-I) exhibited polymer characteristic peaks, with slightly stronger signals of PPD than the SD profiles.

PXRD pattern results support the results of solubility measurements presented previously. Amorphous compounds have a less uniform molecular arrangement than crystalline compounds, and this disorder is the driving force for its greater solubility and faster dissolution rates [65,66]. 
However, some weak characteristic PPD peaks were observed in the PXRD diffractograms of PMs, indicating a polymer influence, which might also be relevant to the preparation method and ratio of the drug and polymers in SD formulation, as mentioned above. However, weaker PPD characteristic peaks were observed in SD diffractograms. This finding indicated that the majority of PPD might be present in an amorphous state in SDs, and a crystalline transformation of PPD is present in the SD formation. The preparation method of solid dispersion was critical in determining the X-ray diffraction pattern. Some reports [61] found that this phenomenon was attributed to either drug conversion to a different polymorph (fusion method) or a conversion to the amorphous state or molecular solution (solvent method).
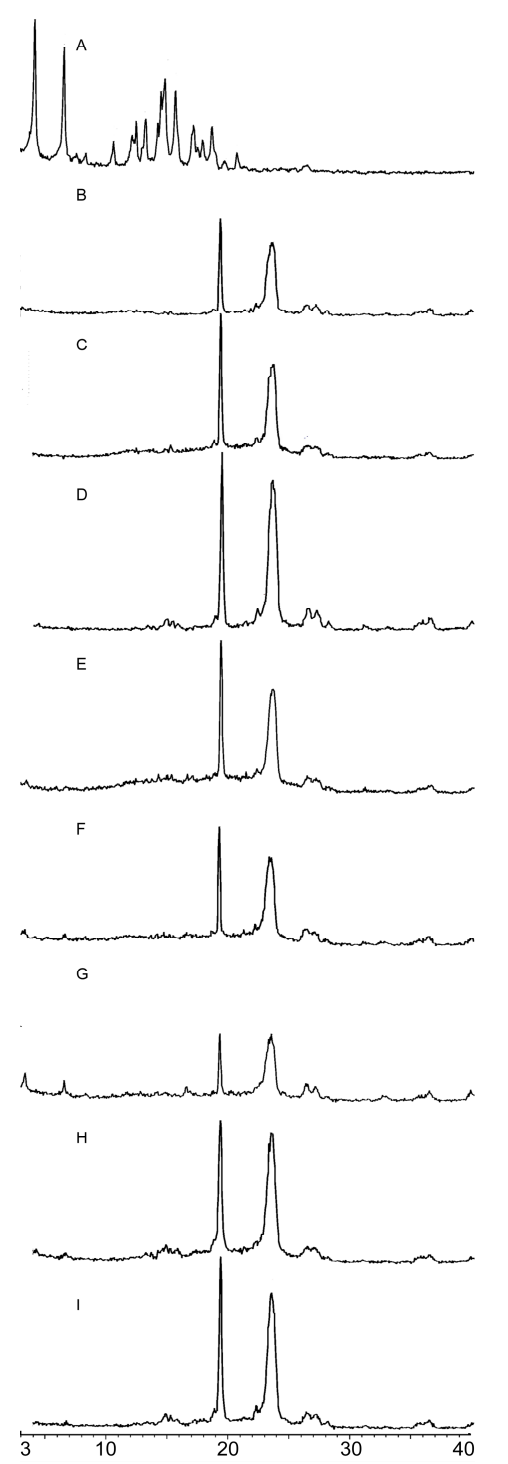

Figure 3. Powder X-ray diffractograms (PXRD) of PPD (A), PEG6000 (B), F68 (C), F1 (D), F2 (E), F3 (F), PEG6000 PM (G), F68 PM (H), PEG6000 and F68 PM (I).

\subsubsection{FTIR Analysis}

As shown in Figure 4A, the FTIR spectra of PPD revealed characteristic peaks at $3221(-\mathrm{O}-\mathrm{H}$ stretching), 2943, 2873 (-C-H stretching), 1120, and $1031 \mathrm{~cm}^{-1}$ (-C-O stretching). PEG6000 and F68 exhibited similar constitutional units $\left(-\mathrm{CH}_{2} \mathrm{CH}_{2} \mathrm{O}\right.$-); therefore, their FTIR spectra (Figure 4B,C) were similar. PEG6000 (Figure 4B) and F68 (Figure 4C) exhibited characteristic peaks close to 2890, 1465, 
and $1110 \mathrm{~cm}^{-1}$. Characteristic PPD and polymer peaks were observed in the SD spectra (Figure 4D-F) and PMs (Figure 4G-I).

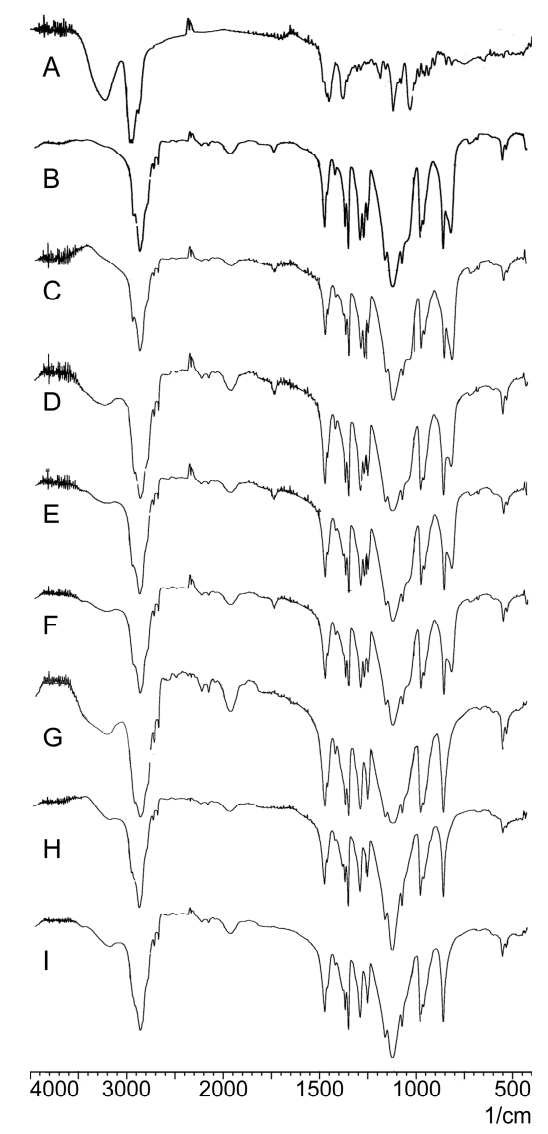

Figure 4. Fourier transform infrared spectroscopy (FTIR) spectra of PPD (A), PEG6000 (B), F68 (C), F1 (D), F2 (E), F3 (F), PEG6000 PM (G), F68 PM (H), PEG6000 and F68 PM (I).

FTIR spectroscopy was used to investigate drug and polymer interactions, which may lead to peak broadening and the bathochromic shift of the absorption bands of interacting functional groups. By comparing the PPD and polymer spectra with those of SDs and PMs (Figure 5), the characteristic PPD and polymer peaks could be identified in SD and PM spectrograms, despite the disappearance of some characteristic peaks. This peak disappearance might be associated with the drug-polymer ratio (1:10). Hence, the existence of polymers might conceal some characteristic PPD peaks. The spectrograms exhibited no new functional groups; moreover, it indicated the lack of chemical reactions between PPD and polymers in SDs $[67,68]$.

\subsubsection{NMR Analysis}

Various feature peaks were observed in the PPD spectra (Figure 5A). A total of eight Hydrogen $(\mathrm{H})$ signals corresponding to eight PPD methyl groups within the range 0.85-1.62 ppm were observed. The H signal at 5.29 ppm represented the PPD olefinic carbon. PEG6000 and F68 signals (Figure 5B,C) almost eliminated the interference in SDs (Figure 5D-F) and PMs (Figure 5G-I), thereby confirming that no new functional groups were present. 


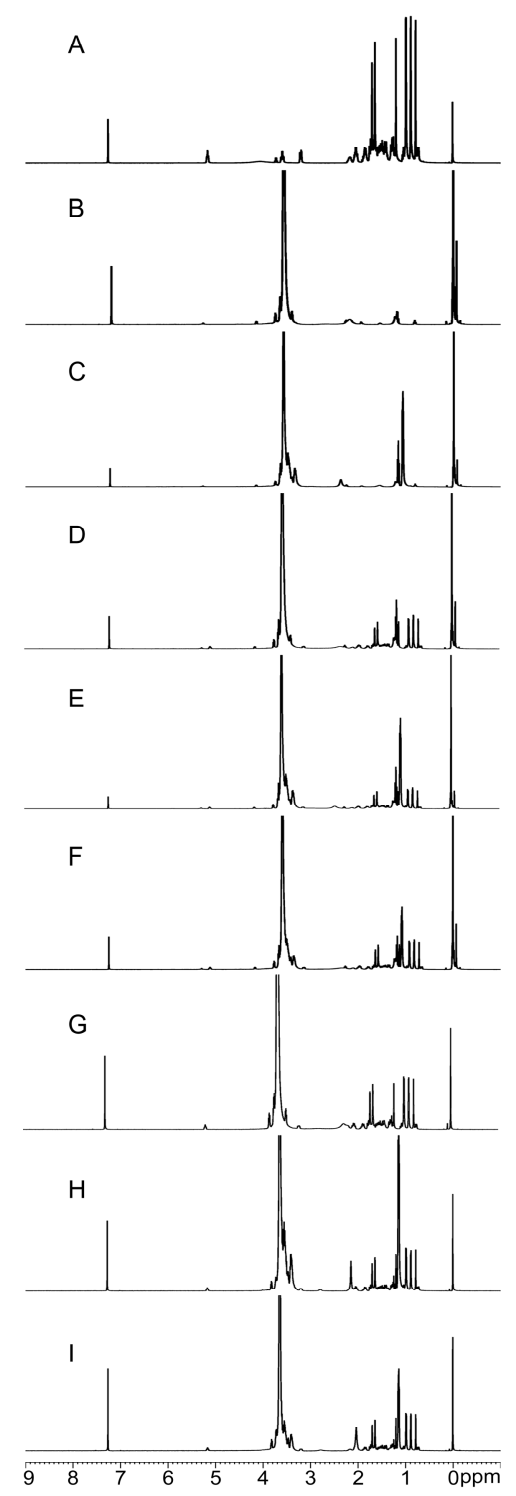

Figure 5. Nuclear magnetic resonance (NMR) spectra of PPD (A), PEG6000 (B), F68 (C), F1 (D), F2 (E), F3 (F), PEG6000 PM (G), F68 PM (H), PEG6000 and F68 PM (I).

${ }^{1} \mathrm{H}-\mathrm{NMR}$ spectra were used to describe the interactions between PPD and PEG, F68, or in both SDs. A comparison of the ${ }^{1} \mathrm{H}-\mathrm{NMR}$ spectra of PPD and polymers with SDs and PMs revealed characteristic PPD peaks in the SD and PM spectra, without forming new characteristic peaks. Furthermore, the position of the characteristic PPD peaks did not change, which suggested lack of interactions between PPD and PEG, F68, or in both SDs [69].

\subsection{Molecular Docking and Dynamics Calculation}

A computational simulation was used to investigate PPD-PEG6000 (F1), PPD-F68 (F2), and PPD-PEG6000-F68 (F3) interactions at the molecular level. Optimized PPD and F68 conformations were initially produced from linear structures. F1 and F2 simulation results (Figure $6 a, b$ ) revealed that the PPD molecule localized to the interpolated charged surface of PEG6000 (or F68) rather than within the amorphous polymer chain network.

The docking-free energy of PPD-PEG6000 (F1) and PPD-F68 (F2) were -3.5 and $-4.5 \mathrm{kcal} \cdot \mathrm{mol}^{-1}$, respectively. These negative values showed that PEG (or F68) could interact with PPD to prevent 
PPD crystal formation. This was consistent with the conclusions of the PXRD and DSC methods. The composite ratio of PPD and PEG6000 (or F68) can be considered as 2:1 according to the experimental data. Therefore, in the molecular docking protocol, two PPD and one PEG6000 (or F68) molecules were used. According to this composite ratio, the equilibrium constants of the PPD and F68 interaction should be greater than that between PPD and PEG6000. The computational result (docking-free energy of PPD-F68 in F2 was lower than that of PPD-PEG6000 in F1) was consistent with this estimation of their interaction. Therefore, we believe that an interaction between PEG6000 and F68 occurred (the interaction energy is $-442 \mathrm{kcal} \cdot \mathrm{mol}^{-1}$ ). These interactions might lead to slight decrease in the PPD-PEG-F68 (F3) drug loading efficiency when compared with PPD-PEG6000 (F1) and PPD-F68 (F2), without any statistical difference $(p>0.05)$, as shown in the DL determination results. Figure 7 shows the most probable interaction conformation between PEG6000 and F68 in F3. However, due to the low concentrations of PEG6000 and F68 in F3, any interaction between them was not very obvious.

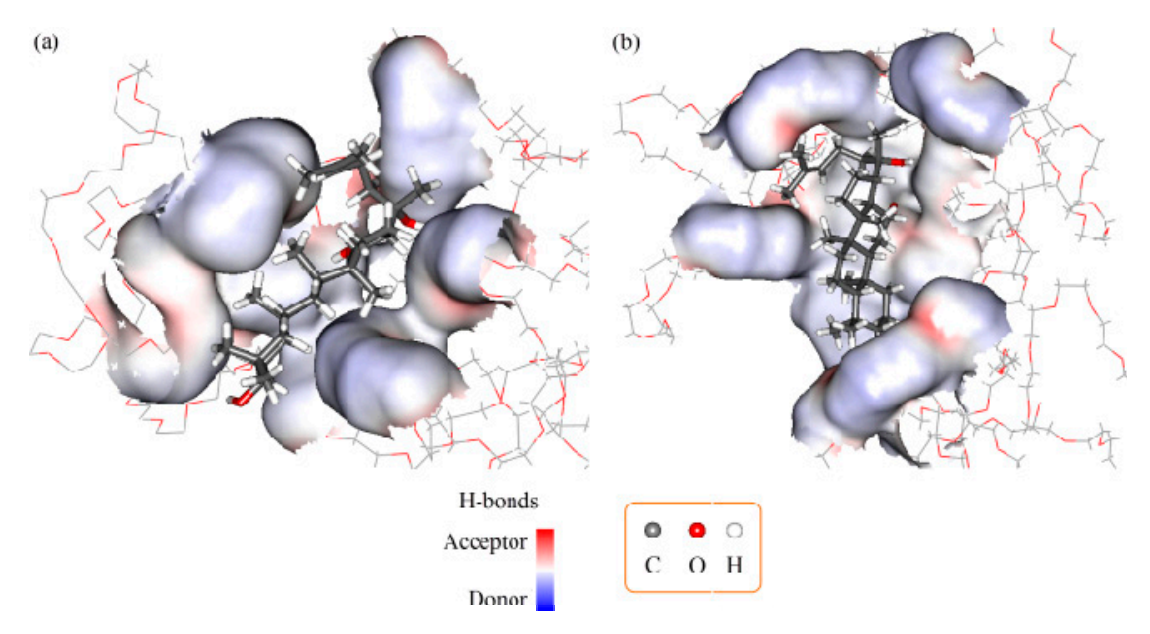

Figure 6. 3D interaction conformations of PPD-F68 in F1 (a) and PPD-PEG6000 in F2 (b).

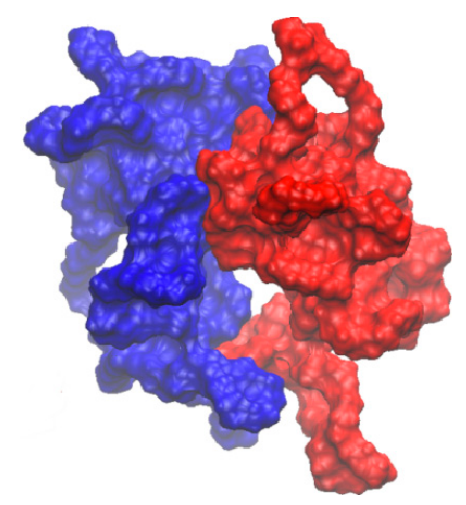

Figure 7. 3D interaction conformations of F68 (Blue) and PEG6000 (Red).

The molecular docking and dynamic study results suggested that the PPD molecule localized to the interpolated charged surface of PEG6000 (or F68), rather than within the amorphous polymer chain network. PEG6000 (or F68) might interact with PPD in order to prevent PPD crystal formation, which helped enhance the PPD dispersity in the polymers. The interaction between PEG6000 and F68 in F3 might lead to a lower drug loading efficiency. However, the effect was not obvious due to the low PEG6000 and F68 concentrations in F3. 


\subsection{In Vitro Dissolution Study}

The in vitro dissolution behaviors of PPD, SDs, and PMs in the dissolution media under sink conditions are shown in Figure 8. Pure PPD had the slowest and lowest dissolution rate, whereas F2 had the fastest and highest dissolution rate. In the first $15 \mathrm{~min}$, each SD exhibited a $60 \%$ dissolution rate, whereas PPD only exhibited a 15\% rate. After $60 \mathrm{~min}$, the SD dissolution profiles gradually increased to $80 \%$. After $120 \mathrm{~min}$, among all of the dissolution profiles, F2 had the highest rate at approximately 99.8\%. F3 and F1 exhibited the second highest rate at approximately $89.6 \%$ and $82.2 \%$, respectively, whereas the dissolution rate of the pure drug was approximately $55.1 \%$. The dissolution speed and rate of the PMs were higher than those of pure PPD, but lower than those of the SDs. The final dissolution rates of all of the SDs significantly differed from that of pure PPD $(p<0.05)$. Furthermore, the F2 dissolution rate significantly differed from that of F1 $(p<0.05)$.

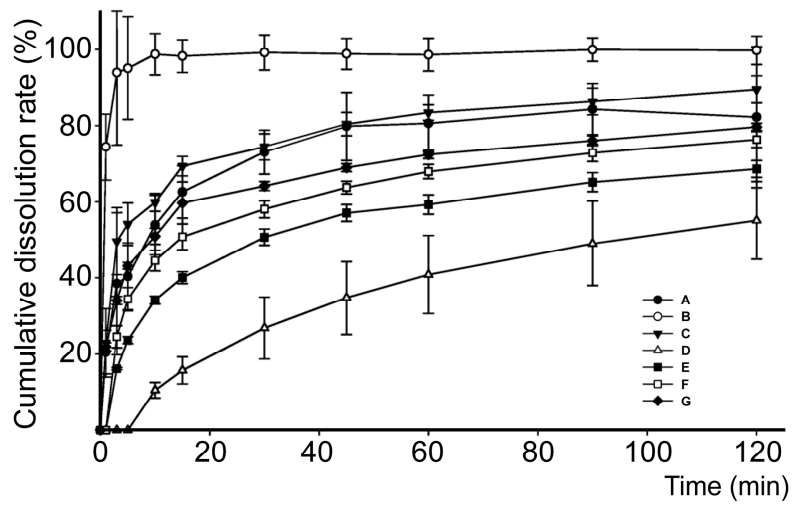

Figure 8. Dissolution profiles of F1 (A), F2 (B), F3 (C), PPD (D), PEG6000 PM (E), F68 PM (F), PEG6000 and F68 PM (G).

The in vitro dissolution performance was measured to evaluate SD effects on promoting in vitro dissolution. The dissolution profile and statistical analyses revealed that F68 was a more suitable SD polymer than PEG6000 for the PPD-SDs formulations. SDs had a higher dissolution rate than PMs. The in vitro dissolution study results suggested that the F68 exerted superiorly favorable effects on the dissolution rate of PPD, whose effects might be related to the solubilization of these hydrophilic polymers. This might contribute to the development of new PPD agents and other poorly soluble drugs [70].

\section{Materials and Methods}

\subsection{Materials}

20(S)-protopanaxadiol (purity > 98\%, No. 111747-200501, National Institutes for Food and Drug Control, Beijing, China), PEG6000 (Sinopharm Chemical Reagent Co., Ltd., Shanghai, China), poloxamer 188 (F68, BASF, Germany), and Tween ${ }^{\circledR}-80$ (T-80, Sinopharm Chemical Reagent Co., Ltd., Shanghai, China) were used in the study. The acetonitrile was of chromatographic grade and purchased from Merck Co. Ltd. Other solvents were of analytical grade.

\subsection{Formulation Design}

SD formulations were composed of PPD (purity > 98\%), T-80, and polymers (PEG6000, F68, and PEG6000 and F68 mixture). The formulations are detailed in Table 1. 
Table 1. SD formulation ratio $(\mathrm{m} / \mathrm{m})$ of PPD with different polymers.

\begin{tabular}{ccccc}
\hline \multirow{2}{*}{ Formulation } & PPD $(\mathrm{g})$ & \multicolumn{2}{c}{ Polymer $(\mathrm{g})$} & \multirow{2}{*}{ Tween-80 $(\mathrm{g})$} \\
\cline { 3 - 4 } & & PEG6000 & F68 & \\
\hline F1 & 0.5 & 5.0 & - & 0.4 \\
F2 & 0.5 & - & 5.0 & 0.4 \\
F3 & 0.5 & 2.5 & 2.5 & 0.4 \\
\hline
\end{tabular}

\subsection{SD Preparation}

SDs were prepared via a melting-solvent method at a mass ratio of 1:10 (drug:polymer). PPD was completely dissolved in the proper amount of absolute alcohol containing T-80 (PPD:absolute alcohol:T-80 $=1: 8: 0.8, \mathrm{~m} / \mathrm{v} / \mathrm{m})$. Subsequently, the solution was transferred into the melting matrix (polymer) in a $80^{\circ} \mathrm{C}$ water bath and stirred for $15 \mathrm{~min}$. The resultant was frozen at $-20{ }^{\circ} \mathrm{C}$ for $24 \mathrm{~h}$, porphyrized by an agate mortar and pestle, and stored in a desiccator at ambient temperature.

\subsection{Physical Mixture Preparation}

PMs were prepared by the simple intensive mixing of PPD and PEG6000 and/or F68 at certain ratios $(1: 10,1: 10$, and 1:5:5, $\mathrm{m} / \mathrm{m})$ in a mortar until homogeneous. Resultant mixtures were sieved and then kept in a desiccator at room temperature until further study.

\subsection{Determination of Drug Loading Efficiency}

The PPD content in the samples was determined through high-performance liquid chromatography (HPLC) using an Agilent 1200 system (Agilent Technologies, Santa Clara, CA, USA) equipped with a UV detector and it was detected at a wavelength of $203 \mathrm{~nm}$. The separation was performed using a XB-C18 column (Welch, Shanghai, China; $5 \mu \mathrm{m}, 4.6 \mathrm{~mm} \times 250 \mathrm{~mm}$ ). The mobile phase was composed of acetonitrile and deionized water $(88: 12, v / v)$ and eluted at a rate of $1.0 \mathrm{~mL} / \mathrm{min}$. The column temperature was maintained at $25{ }^{\circ} \mathrm{C}$. The drug loading (DL) efficiency was measured as follows. After the prepared SD was completely dissolved in methanol, the supernatant was withdrawn and filtered through a membrane filter $(0.45 \mu \mathrm{m})$. The amount of PPD in the resulting solution was quantitatively analyzed using HPLC. Each sample was measured in triplicate. Lastly, the DL was calculated using the following equation:

$$
\mathrm{DL}(\%)=\frac{\text { Amount of PPD in SDs }}{\text { Amount of SDs }} \times 100 \%
$$

\subsection{Characterization of $S D s$}

\subsubsection{DSC Analysis}

Physicochemical properties of PPD in SDs were evaluated through DSC. Before testing, the solid sample was dried at $40{ }^{\circ} \mathrm{C}$ to remove residual water. PPD, SDs, and PMs were analyzed under a nitrogen atmosphere through DSC (DSC-Q2000, TA Instruments, New Castle, DE, USA), and each sample was heated at $10^{\circ} \mathrm{C} / \mathrm{min}$ from $25^{\circ} \mathrm{C}$ to $300^{\circ} \mathrm{C}$.

\subsubsection{PXRD Analysis}

PXRD patterns were evaluated via PXRD (Bruker D8 Advance). Samples were exposed to $\mathrm{Cu}$ radiation under $40 \mathrm{~mA}$ and $40 \mathrm{kV}$. The scanning angle $(2 \theta)$ ranged from $3^{\circ}$ to $40^{\circ}$ at $1^{\circ} / \mathrm{s}$.

\subsubsection{FTIR Analysis}

FTIR was performed using a Fourier transform infrared spectrophotometer (FTIR Presitage 21 Fourier Transform Infrared Spectrophotometer, Shimadzu). Potassium bromide discs were prepared 
by mixing a small amount of the sample with potassium bromide and compressing the mixture. The frequency ranged from $4000 \mathrm{~cm}^{-1}$ to $400 \mathrm{~cm}^{-1}$.

\subsubsection{Nuclear Magnetic Resonance}

The ${ }^{1} \mathrm{H}-\mathrm{NMR}$ spectra [71] for SDs were analyzed by an AVANCE III $400 \mathrm{MHz}$ UltraShield-PlusTM (Bruker, Karlsruhe, Germany) NMR spectrometer using deuterated chloroform $\left(\mathrm{CDCl}_{3}\right)$ as the solvent.

\subsection{Molecular Docking and Dynamics Calculation}

PPD molecular structure was extracted from the single crystal structure of 20-O- $\beta$-glucopyranosyl20(S)-protopanaxadiol dehydrate obtained from Cambridge Structural Database (Refcode: JEPJEU) and reconstructed. PEG6000 and F68 molecular structures were constructed manually. The molecular dynamics program Amber 12 (University of California, San Francisco, CA, USA) was used for energy minimization and molecular dynamics calculation. AmberTools in Amber 12 was used to prepare Amber starting stuffs. Partial atomic charges of PEG6000 or F68 units were calculated via Gaussian 09 package. The docking program AutoDock Vina 1.1.2 (The Scripps Research Institute, San Diego, CA, USA) [72] was used to perform an automated molecular docking calculation.

Firstly, energy minimization protocol was executed to prepare PPD, PEG6000, and F68 models. Then, a 20 ns molecular dynamics simulation was run for PEG6000 and F68. Following this, the 10 highest scoring conformation with one or two PPD molecules separately docked to PEG6000 or F68 molecule were generated. Finally, one conformation with relatively low energy was used for the optimization of the successive structure.

During the minimization protocol, all models were placed under vacuum. Optimized PEG6000 and F68 molecules were put into separated water boxes, which had a $10 \AA$ width. Then, a $20 \mathrm{~ns}$ molecular dynamics simulation was performed. A non-bond cutoff distance of $18.5 \AA$, spline width of $1.0 \AA$, and buffer width of $0.5 \AA$ were used. During the docking protocol, a Lamarckian Genetic Algorithm (LGA) combined with a grid-based energy evaluation method were used for pre-calculating grid maps according to the interatomic potentials of all of the atom types present in the host and guest molecules, including Lennard-Jones potentials for van der Waals interactions and Coulomb potentials for electrostatic interactions. A grid map of dimensions $80 \AA \times 80 \AA \times 80 \AA$, with a grid spacing of $0.375 \AA$, was used to cover the F68 or PEG6000 structure. Using AutoDockTools (Version 1.4.5, The Scripps Research Institute, La Jolla, CA, USA), the atomic partial charges were calculated using the Gasteiger-Marsili method [73]. Parameters used for the global search included an initial population of 50 individuals, with a maximal number of energy evaluations of 1,500,000, and a maximal number of generations of 50,000 as an end criterion. The Autodock Vina scoring function, which is based on experience, and other docking parameters were set to default.

\subsection{Solubility Measurements}

The water solubility was determined by a modified shake-flask method [74,75]. Excess SDs were dispersed in $5 \mathrm{~mL}$ distilled water and shaken at $100 \mathrm{r} / \mathrm{min}$ and $37^{\circ} \mathrm{C}$ for $24 \mathrm{~h}$. Samples were then centrifuged at 12,000 $\mathrm{r} / \mathrm{min}$ for $5 \mathrm{~min}$. The resultant supernatant was withdrawn and filtered using a $0.45 \mu \mathrm{m}$ membrane. The PPD content in the saturated solution was determined by the HPLC method, as previously described.

\subsection{In Vitro Dissolution Study}

The in vitro dissolution studies of PPD, SDs, and PMs were performed using a Chinese Pharmacopoeia (2015) type III dissolution apparatus [70,76,77]. The dissolution media was comprised of $200 \mathrm{~mL}$ distilled water, containing $0.35 \% \mathrm{~T}-80$ at $37 \pm 0.5^{\circ} \mathrm{C}$. The stirring speed was $100 \mathrm{r} / \mathrm{min}$. PMs and SDs of the formulations, containing approximately equivalent amounts of $8 \mathrm{mg}$ PPD, were immersed into the dissolution media. Sample solutions of $2.0 \mathrm{~mL}$ were withdrawn at specific time intervals and filtered with a $0.45 \mu \mathrm{m}$ membrane for sample analysis. Furthermore, preheated fresh 
media of an equal volume was added for compensation at every withdrawal. PPD concentration in the samples was determined by HPLC, as previously described, and the cumulative drug dissolution rate at each time point was profiled. Each experiment was performed in triplicate.

\subsection{Statistical Analysis}

All data are presented as mean \pm standard deviation or mean. The statistical significance of the differences was determined using ANOVA. In all tests, $p<0.05$ was considered significant. Data analysis was performed with the SPSS software package (Version 19.0, IBM, NY, USA).

\section{Conclusions}

In this study, SDs were prepared with different polymers, and SD formations were characterized via different analytical methods. DSC and PXRD analyses results indicated that SD crystallinity reduced significantly, whereas the majority of PPD in SDs existed in an amorphous state. Furthermore, no interaction was observed between the PPD and polymers on FTIR and NMR spectra. Molecular docking and dynamic calculations indicated that the PPD molecule localized to the interpolated charged surface of PEG6000 (or F68) rather than within the amorphous polymer chain network, which might have helped prevent PPD crystal formation consequently enhancing the PPD dispersity in the polymers. An in vitro dissolution study revealed that, compared with pure PPD, SDs considerably improved the dissolution performance in distilled water $(0.35 \% \mathrm{~T}-80)$. Furthermore, among three SD formulations, F68 was the most effective in improving the PPD solubility and was superior to F68 and PEG6000 (1:1).

Consequently, this study revealed the potential of SDs to increase PPD solubility and dissolution performance. As a pharmaceutical intermediate, SDs can be further processed into tablets [78], capsules [79], pills [80], and other formulations. However, in vivo studies on PPD are needed for further comprehensive evaluation of its SD products.

Acknowledgments: This work was financially supported by the programs of the National Natural Science Foundation of China (No. 81303233) and the Foundation of Shanghai Science and Technology Commission (No. 13401900300).

Author Contributions: B.W. and Z.C. contributed to the conception of the study; T.T.D. and T.G. significantly contributed to the data analysis in the section of molecular docking and corresponding manuscript preparation; Q.Z. and Y.P. performed the data analyses and wrote the manuscript; Y.W. and T.Z. contributed to the constructive discussions. All authors read and approved the manuscript.

Conflicts of Interest: The authors report no conflicts of interest in this work.

\section{References}

1. Helms, S. Cancer Prevention and Therapeutics: Panax Ginseng. Altern. Med. Rev. 2004, 9, 259-274. [PubMed]

2. Xiang, Y.Z.; Shang, H.C.; Gao, X.M.; Zhang, B.L. A comparison of the ancient use of ginseng in traditional Chinese medicine with modern pharmacological experiments and clinical trials. Phytother. Res. 2008, 22, 851-858. [CrossRef] [PubMed]

3. Chen, C.F.; Chiou, W.F.; Zhang, J.T. Comparison of the pharmacological effects of Panax ginseng and Panax quinquefolium. Acta Pharmacol. Sin. 2008, 29, 1103-1108. [CrossRef] [PubMed]

4. Wang, W.; Zhao, Y.; Rayburn, E.R.; Hill, D.L.; Wang, H.; Zhang, R. In vitro anti-cancer activity and structure-activity relationships of natural products isolated from fruits of Panax ginseng. Cancer Chemother. Pharmacol. 2007, 59, 589-601. [CrossRef] [PubMed]

5. Radad, K.; Gille, G.; Liu, L.; Rausch, W.-D. Use of Ginseng in Medicine with Emphasis on Neurodegenerative Disorders. J. Pharmacol. Sci. 2006, 100, 175-186. [CrossRef] [PubMed]

6. Anoja, S.A.; Ji, A.W.; Yuan, C.-S. Ginseng pharmacology - Multiple constituents and multiple actions. Biochem. Pharmacol. 1999, 58, 1685-1693.

7. Kennedy, O.D.; Scholey, B.A. Ginseng: Potential for the enhancement of cognitive performance and mood. Pharmacol. Biochem. Behav. 2003, 75, 687-700. [CrossRef] 
8. Endale, M.; Im, E.J.; Lee, J.Y.; Kim, S.D.; Yayeh, T.; Song, Y.B.; Kwak, Y.S.; Kim, C.; Kim, S.H.; Roh, S.S.; et al. Korean Red Ginseng Saponin Fraction Rich in Ginsenoside-Rb1, Rc and Rb2 Attenuates the Severity of Mouse Collagen-Induced Arthritis. Mediat. Inflamm. 2014, 2014, 748964:1-748964:14. [CrossRef] [PubMed]

9. Yang, W.Z.; Hu, Y.; Wu, W.Y.; Ye, M.; Guo, D.A. Saponins in the genus Panax L. (Araliaceae): A systematic review of their chemical diversity. Phytochemistry 2014, 106, 7-24. [CrossRef] [PubMed]

10. Kim, T.; Choi, H.; Kim, N.; Kim, D. Anxiolytic-like Effects of Ginsenosides Rg3 and Rh2 from Red Ginseng in the Elevated Plus-Maze Model. Planta Med. 2009, 75, 836-839. [CrossRef] [PubMed]

11. Lu, J.; Yao, Q.; Chen, C. Ginseng Compounds: An Update on their Molecular Mechanisms and Medical Applications. Curr. Vasc. Pharmacol. 2009, 7, 293-302. [CrossRef] [PubMed]

12. Nag, S.A.; Qin, J.J.; Wang, W.; Wang, M.H.; Wang, H.; Zhang, R. Ginsenosides as Anticancer Agents: In vitro and in vivo Activities, Structure-Activity Relationships, and Molecular Mechanisms of Action. Front. Pharmacol. 2012, 3, 25. [CrossRef] [PubMed]

13. Dong, H.; Bai, L.P.; Wong, V.K.; Zhou, H.; Wang, J.R.; Liu, Y.; Jiang, Z.H.; Liu, L. The In Vitro Structure-Related Anti-Cancer Activity of Ginsenosides and Their Derivatives. Molecules 2011, 16, 10619-10630. [CrossRef] [PubMed]

14. Li, H.; Ye, M.; Guo, H.; Tian, Y.; Zhang, J.; Zhou, J.; Hu, Y.; Guo, D. Biotransformation of 20(S)-protopanaxadiol by Mucor spinosus. Phytochemistry 2009, 70, 1416-1420. [CrossRef] [PubMed]

15. Liu, L.; Zhu, X.M.; Wang, Q.J.; Zhang, D.L.; Fang, Z.M.; Wang, C.Y.; Wang, Z.; Sun, B.S.; Wu, H.; Sung, C.K. Enzymatic preparation of 20(S, R)-protopanaxadiol by transformation of 20(S, R)-Rg3 from black ginseng. Phytochemistry 2010, 71, 1514-1520. [CrossRef] [PubMed]

16. Yoo, M.H.; Yeom, S.J.; Park, C.S.; Lee, K.W.; Oh, D.K. Production of aglycon protopanaxadiol via compound K by a thermostable $\beta$-glycosidase from Pyrococcus furiosus. Appl. Microbiol. Biotechnol. 2011, 89, 1019-1028. [CrossRef] [PubMed]

17. Yu, H.; Zhang, C.; Lu, M.; Sun, F.; Fu, Y.; Jin, F. Purification and characterization of new special ginsenosidase hydrolyzing multi-glycisides of protopanaxadiol ginsenosides, ginsenosidase type I. Chem. Pharm. Bull. 2007, 55, 231-235. [CrossRef] [PubMed]

18. Lee, S.-J.; Sung, J.-H.; Lee, S.-J.; Moon, C.-K.; Lee, B.-H. Antitumor activity of a novel ginseng saponin metabolite in human pulmonary adenocarcinoma cells resistant to cisplatin. Cancer Lett. 1999, 144, $39-43$. [CrossRef]

19. Hasegawa, H.; Lee, K.-S.; Nagaoka, T.; Tezuka, Y.; Uchiyama, M.; Kadota, S.; Saiki, I. Pharmacokinetics of ginsenoside deglycosylated by intestinal bacteria and its transformation to biologically active fatty acid esters. Biol. Pharm. Bull. 2000, 23, 298-304. [CrossRef] [PubMed]

20. Lee, S.; Ko, W.; Kim, J.; Sung, J.; Moon, C.; Lee, B. Induction of apoptosis by a novel intestinal metabolite of ginseng saponin via cytochrome $c$-mediated activation of caspase-3 protease. Biochem. Pharmacol. 2000, 60, 677-685. [CrossRef]

21. Bae, E.; Han, M.; Choo, M.; Park, S.; Kim, D. Metabolism of 20(S)- and 20(R)-Ginsenoside R $\mathrm{g}_{3}$ by Human Intestinal Bacteria and Its Relation to in Vitro Biological Activities. Biol. Pharm. Bull. 2002, 25, 58-63. [CrossRef] [PubMed]

22. Yu, Y.; Zhou, Q.; Hang, Y.; Bu, X.; Jia, W. Antiestrogenic effect of 20S-protopanaxadiol and its synergy with tamoxifen on breast cancer cells. Cancer 2007, 109, 2374-2382. [CrossRef] [PubMed]

23. Li, G.; Wang, Z.; Sun, Y.; Liu, K.; Wang, Z. Ginsenoside 20(S)-Protopanaxadiol Inhibits the Proliferation and Invasion of Human Fibrosarcoma HT1080 cells. Basic Clin. Pharmacol. Toxicol. 2006, 98, 588-592. [CrossRef] [PubMed]

24. Wakabayashi, C.; Murakami, K.; Hasegawa, H.; Murata, J.; Saiki, I. An intestinal bacterial metabolite of ginseng protopanaxadiol saponins has the ability to induce apoptosis in tumor cells. Biochem. Biophys. Res. Commun. 1998, 246, 725-730. [CrossRef] [PubMed]

25. Hang, M.H.; Chen, J.; Chen, S.L.; Wang, X.T. Preparation and study in vitro of 20(S)-protopanaxadiol pharmacosome. China J. Chin. Mater. Med. 2010, 35, 842-846. (in Chinese).

26. Wang, B.; Wang, Y.; Pu, Y.; Xu, B.; Tao, J.; Zhang, T. Apparent Oil/water Partition Coefficient of 20(S)-PPD and Its Intestinal Absorption in Rats. Chin. J. Inf. Tradit. Chin. Med. 2011, 18, 50-61. 
27. Xie, H.T.; Wang, G.J.; Sun, J.G.; Tucker, I.; Zhao, X.C.; Xie, Y.Y.; Li, H.; Jiang, X.L.; Wang, R.; Xu, M.J.; et al. High performance liquid chromatographic-mass spectrometric determination of ginsenoside $\operatorname{Rg} 3$ and its metabolites in rat plasma using solid-phase extraction for pharmacokinetic studies. J. Chromatogr. Anal. Technol. Biomed. Life Sci. 2005, 818, 167-173. [CrossRef] [PubMed]

28. Li, L.; Chen, X.; Li, D.; Zhong, D. Identification of 20(S)-Protopanaxadiol Metabolites in Human Liver Microsomes and Human Hepatocytes. Drug Metab. Dispos. Biol. Fate Chem. 2011, 39, 472-483. [CrossRef] [PubMed]

29. Wang, W.; Wu, X.; Wang, L.; Meng, Q.; Liu, W. Stereoselective Property of 20(S)-Protopanaxadiol Ocotillol Type Epimers Affects Its Absorption and Also the Inhibition of P-Glycoprotein. PLoS ONE 2014, 9, e98887. [CrossRef] [PubMed]

30. Tran, P.H.; Tran, T.T.; Park, J.B.; Lee, B.J. Controlled release systems containing solid dispersions: Strategies and mechanisms. Pharm. Res. 2011, 28, 2353-2378. [CrossRef] [PubMed]

31. Shaikh, S.M.; Avachat, A.M. Enhancement of solubility and permeability of candesartan cilexetil by using different pharmaceutical interventions. Curr. Drug Deliv. 2011, 8, 346-353. [CrossRef] [PubMed]

32. Verma, S.; Rudraraju, V.S. A systematic approach to design and prepare solid dispersions of poorly water-soluble drug. AAPS PharmSciTech 2014, 15, 641-657. [CrossRef] [PubMed]

33. Sinha, S.; Ali, M.; Baboota, S.; Ahuja, A.; Kumar, A.; Ali, J. Solid dispersion as an approach for bioavailability enhancement of poorly water-soluble drug ritonavir. AAPS PharmSciTech 2010, 11, 518-527. [CrossRef] [PubMed]

34. Heo, M.; Piao, Z.; Kim, T.; Cao, Q.; Kim, A.; Lee, B. Effect of solubilizing and microemulsifying excipients in polyethylene glycol 6000 solid dispersion on enhanced dissolution and bioavailability of ketoconazole. Arch. Pharm. Res. 2005, 28, 604-611. [CrossRef] [PubMed]

35. Al-Obaidi, H.; Buckton, G. Evaluation of griseofulvin binary and ternary solid dispersions with HPMCAS. AAPS PharmSciTech 2009, 10, 1172-1177. [CrossRef] [PubMed]

36. Patel, A.R.; Joshi, V.Y. Evaluation of SLS: APG mixed surfactant systems as carrier for solid dispersion. AAPS PharmSciTech 2008, 9, 583-590. [CrossRef] [PubMed]

37. Leuner, C.; Dressman, J. Improving drug solubility for oral delivery using solid dispersions. Eur. J. Pharm. Biopharm. 2000, 50, 47-60. [CrossRef]

38. Damian, F.; Blaton, N.; Kinget, R.; Mooter, G.V.d. Physical stability of solid dispersions of the antiviral agent UC-781 with PEG 6000, Gelucire ${ }^{\circledR} 44 / 14$ and PVP K30. Int. J. Pharm. 2002, 244, 87-98. [CrossRef]

39. Ahuja, N.; Katare, O.P.; Singh, B. Studies on dissolution enhancement and mathematical modeling of drug release of a poorly water-soluble drug using water-soluble carriers. Eur. J. Pharm. Biopharm. 2007, 65, $26-38$. [CrossRef] [PubMed]

40. Kolasinac, N.; Kachrimanis, K.; Homsek, I.; Grujic, B.; Ethuric, Z.; Ibric, S. Solubility enhancement of desloratadine by solid dispersion in poloxamers. Int. J. Pharm. 2012, 436, 161-170. [CrossRef] [PubMed]

41. Dong, Z.; Chatterji, A.; Sandhu, H.; Choi, D.S.; Chokshi, H.; Shah, N. Evaluation of solid state properties of solid dispersions prepared by hot-melt extrusion and solvent co-precipitation. Int. J. Pharm. 2008, 355, 141-149. [CrossRef] [PubMed]

42. Biswal, S.; Sahoo, J.; Murthy, P.N.; Giradkar, R.P.; Avari, J.G. Enhancement of dissolution rate of gliclazide using solid dispersions with polyethylene glycol 6000. AAPS PharmSciTech 2008, 9, 563-570. [CrossRef] [PubMed]

43. Vo, C.L.; Park, C.; Lee, B.J. Current trends and future perspectives of solid dispersions containing poorly water-soluble drugs. Eur. J. Pharm. Biopharm. 2013, 85, 799-813. [CrossRef] [PubMed]

44. Wlodarski, K.; Sawicki, W.; Haber, K.; Knapik, J.; Wojnarowska, Z.; Paluch, M.; Lepek, P.; Hawelek, L.; Tajber, L. Physicochemical properties of tadalafil solid dispersions-Impact of polymer on the apparent solubility and dissolution rate of tadalafil. Eur. J. Pharm. Biopharm. 2015, 94, 106-115. [CrossRef] [PubMed]

45. Nagy, Z.K.; Balogh, A.; Demuth, B.; Pataki, H.; Vigh, T.; Szabo, B.; Molnar, K.; Schmidt, B.T.; Horak, P.; Marosi, G.; et al. High speed electrospinning for scaled-up production of amorphous solid dispersion of itraconazole. Int. J. Pharm. 2015, 480, 137-142. [CrossRef] [PubMed]

46. Sun, M.; Wu, C.; Fu, Q.; Di, D.; Kuang, X.; Wang, C.; He, Z.; Wang, J.; Sun, J. Solvent-shift strategy to identify suitable polymers to inhibit humidity-induced solid-state crystallization of lacidipine amorphous solid dispersions. Int. J. Pharm. 2016, 503, 238-246. [CrossRef] [PubMed] 
47. Craig, D. The mechanisms of drug release from solid dispersions in water-soluble polymers. Int. J. Pharm. 2002, 231, 131-144. [CrossRef]

48. Vasconcelos, T.; Sarmento, B.; Costa, P. Solid dispersions as strategy to improve oral bioavailability of poor water soluble drugs. Drug Discov. Today 2007, 12, 1068-1075. [CrossRef] [PubMed]

49. Karavas, E.; Ktistis, G.; Xenakis, A.; Georgarakis, E. Effect of hydrogen bonding interactions on the release mechanism of felodipine from nanodispersions with polyvinylpyrrolidone. Eur. J. Pharm. Biopharm. 2006, 63, 103-114. [CrossRef] [PubMed]

50. Muhrer, G.; Meier, U.; Fusaro, F.; Albano, S.; Mazzotti, M. Use of compressed gas precipitation to enhance the dissolution behavior of a poorly water-soluble drug: Generation of drug microparticles and drug-polymer solid dispersions. Int. J. Pharm. 2006, 308, 69-83. [CrossRef] [PubMed]

51. Moschwitzer, J.P. Drug nanocrystals in the commercial pharmaceutical development process. Int. J. Pharm. 2013, 453, 142-156. [CrossRef] [PubMed]

52. Pouton, C.W. Formulation of poorly water-soluble drugs for oral administration: Physicochemical and physiological issues and the lipid formulation classification system. Eur. J. Pharm. Sci. Off. J. Eur. Fed. Pharm. Sci. 2006, 29, 278-287. [CrossRef] [PubMed]

53. Cho, Y.; Ha, E.S.; Baek, I.H.; Kim, M.S.; Cho, C.W.; Hwang, S.J. Enhanced supersaturation and oral absorption of sirolimus using an amorphous solid dispersion based on Eudragit ${ }^{\circledR}$ E. Molecules 2015, 20, 9496-9509. [CrossRef] [PubMed]

54. Yu, D.G.; Zhu, L.M.; Branford-White, C.J.; Yang, J.H.; Wang, X.; Li, Y.; Qian, W. Solid dispersions in the form of electrospun core-sheath nanofibers. Int. J. Nanomed. 2011, 6, 3271-3280. [CrossRef] [PubMed]

55. Han, M.; Chen, J.; Wang, Y.; Chen, S.; Wang, X. Determination of 20(S)-protopanaxadiol in rat plasma by LC-MS/MS and its application to the pharmacokinetic study: A comparative study of its solution and two oral formulations. J. Anal. Chem. 2013, 68, 730-735. [CrossRef]

56. Han, M.; Chen, J.; Chen, S.; Wang, X. Development of a UPLC-ESI-MSMS Assay for 20(S)-Protopanaxadiol and Pharmacokinetic Application of its Two Formulations in Rats. Anal. Sci. 2010, 26, 749-753. [CrossRef] [PubMed]

57. Jin, X.; Zhang, Z.H.; Li, S.L.; Sun, E.; Tan, X.B.; Song, J.; Jia, X.B. A nanostructured liquid crystalline formulation of 20(S)-protopanaxadiol with improved oral absorption. Fitoterapia 2013, 84, 64-71. [CrossRef] [PubMed]

58. Musende, A.G.; Eberding, A.; Wood, C.A.; Adomat, H.; Fazli, L.; Hurtado-Coll, A.; Jia, W.; Bally, M.B.; Tomlinson Guns, E.S. A novel oral dosage formulation of the ginsenoside aglycone protopanaxadiol exhibits therapeutic activity against a hormone-insensitive model of prostate cancer. Anti-Cancer Drugs 2012, 23, 543-552. [CrossRef] [PubMed]

59. Wang, B.; Pu, Y.; Xu, B.; Tao, J.; Wang, Y.; Zhang, T.; Wu, P. Self-Microemulsifying Drug Delivery System Improved Oral Bioavailability of 20(S)-protopanaxadiol: From preparation to evaluation. Chem. Pharm. Bull. 2015, 63, 688-693. [CrossRef] [PubMed]

60. Lee, S.; Park, Y.; Jang, J.; Hur, B.; Chi, S. Solid dispersions containing 20-O- $\beta$-D-Glucopyranosyl-20(S)protopanaxadiol. EP2510924 (A1), 18 May 2012.

61. Eloy, J.O.; Marchetti, J.M. Solid dispersions containing ursolic acid in Poloxamer 407 and PEG 6000: A comparative study of fusion and solvent methods. Powder Technol. 2014, 253, 98-106. [CrossRef]

62. Kreidel, R.N.; Duque, M.D.; Serra, C.H.R.; Velasco, M.V.R.; Baby, A.R.; Kaneko, T.M.; Consiglieri, V.O. Dissolution Enhancement and Characterization of Nimodipine Solid Dispersions with Poloxamer 407 or PEG 6000. J. Dispers. Sci. Technol. 2012, 33, 1354-1359. [CrossRef]

63. Newa, M.; Bhandari, K.H.; Li, D.X.; Kwon, T.H.; Kim, J.A.; Yoo, B.K.; Woo, J.S.; Lyoo, W.S.; Yong, C.S.; Choi, H.G. Preparation, characterization and in vivo evaluation of ibuprofen binary solid dispersions with poloxamer 188. Int. J. Pharm. 2007, 343, 228-237. [CrossRef] [PubMed]

64. Newa, M.; Bhandari, K.H.; Oh, D.H.; Kim, Y.R.; Sung, J.H.; Kim, J.O.; Woo, J.S.; Choi, H.G.; Yong, C.S. Enhanced dissolution of ibuprofen using solid dispersion with poloxamer 407. Arch. Pharm. Res. 2008, 31, 1497-1507. [CrossRef] [PubMed]

65. Shah, B.; Kakumanu, V.K.; Bansal, A.K. Analytical techniques for quantification of amorphous/crystalline phases in pharmaceutical solids. J. Pharm. Sci. 2006, 95, 1641-1665. [CrossRef] [PubMed] 
66. Borba, P.A.; Pinotti, M.; de Campos, C.E.; Pezzini, B.R.; Stulzer, H.K. Sodium alginate as a potential carrier in solid dispersion formulations to enhance dissolution rate and apparent water solubility of BCS II drugs. Carbohydr. Polym. 2016, 137, 350-359. [CrossRef] [PubMed]

67. Verheyen, S.; Blaton, N.; Kinget, R.; Mooter, G.V.D. Mechanism of increased dissolution of diazepam and temazepam from polyethylene glycol 6000 solid dispersions. Int. J. Pharm. 2002, 249, 45-58. [CrossRef]

68. Damian, F.; Blaton, N.; Naesens, L.; Balzarini, J.; Kinget, R.; Augustijns, P.; Mooter, G.V.D. Physicochemical characterization of solid dispersions of the antiviral agent UC-781 with polyethylene glycol 6000 and Gelucire 44/14. Eur. J. Pharm. Sci. 2000, 10, 311-322. [CrossRef]

69. Guedes, F.L.; de Oliveira, B.G.; Hernandes, M.Z.; De Simone, C.A.; Veiga, F.J.; de Lima Mdo, C.; Pitta, I.R.; Galdino, S.L.; Neto, P.J. Solid dispersions of imidazolidinedione by PEG and PVP polymers with potential antischistosomal activities. AAPS PharmSciTech 2011, 12, 401-410. [CrossRef] [PubMed]

70. Xia, H.J.; Zhang, Z.H.; Jin, X.; Hu, Q.; Chen, X.Y.; Jia, X.B. A novel drug-phospholipid complex enriched with micelles: Preparation and evaluation in vitro and in vivo. Int. J. Nanomed. 2013, 8, 545-554. [CrossRef] [PubMed]

71. Onoue, S.; Kojo, Y.; Suzuki, H.; Yuminoki, K.; Kou, K.; Kawabata, Y.; Yamauchi, Y.; Hashimoto, N.; Yamada, S. Development of novel solid dispersion of tranilast using amphiphilic block copolymer for improved oral bioavailability. Int. J. Pharm. 2013, 452, 220-226. [CrossRef] [PubMed]

72. Trott, O.; Olson, A.J. AutoDock Vina: Improving the speed and accuracy of docking with a new scoring function, efficient optimization, and multithreading. J. Comput. Chem. 2010, 31, 455-461. [CrossRef] [PubMed]

73. Gasteiger, J.; Marsili, M. Iterative partial equalization of orbital lectronegativity-A rapid access to atomic charges. Tetrahedron 1980, 36, 3219-3228. [CrossRef]

74. Lin, Q.; Ling, L.Q.; Guo, L.; Gong, T.; Sun, X.; Zhang, Z.R. Intestinal absorption characteristics of imperialine: In vitro and in situ assessments. Acta Pharm. Sin. 2015, 36, 863-873. [CrossRef] [PubMed]

75. Lei, Y.; Kong, Y.; Sui, H.; Feng, J.; Zhu, R.; Wang, W. Enhanced oral bioavailability of glycyrrhetinic acid via nanocrystal formulation. Drug Deliv. Transl. Res. 2016, 6, 1-7. [CrossRef] [PubMed]

76. Zulal, N.A.; Lakshmi, P.K. Enhancement of Solubility and Bioavailability of Candesartan Cilexetil using Natural P-Glycoprotein Inhibitors. Trop. J. Pharm. Res. 2015, 14, 21. [CrossRef]

77. Truong, D.H.; Tran, T.H.; Ramasamy, T.; Choi, J.Y.; Choi, H.-G.; Yong, C.S.; Kim, J.O. Preparation and characterization of solid dispersion using a novel amphiphilic copolymer to enhance dissolution and oral bioavailability of sorafenib. Powder Technol. 2015, 283, 260-265. [CrossRef]

78. Won, D.H.; Kim, M.S.; Lee, S.; Park, J.S.; Hwang, S.J. Improved physicochemical characteristics of felodipine solid dispersion particles by supercritical anti-solvent precipitation process. Int. J. Pharm. 2005, 301, 199-208. [CrossRef] [PubMed]

79. Six, K.; Daems, T.; de Hoon, J.; van Hecken, A.; Depre, M.; Bouche, M.P.; Prinsen, P.; Verreck, G.; Peeters, J.; Brewster, M.E.; et al. Clinical study of solid dispersions of itraconazole prepared by hot-stage extrusion. Eur. J. Pharm. Sci. 2005, 24, 179-186. [CrossRef] [PubMed]

80. Qiu, M.-F.; Jia, W.; Li, S.-S.; Xu, Z.-H.; Sun, X.; Wang, X.-R.; Zhang, Y.-Y.; Xie, G.-X. A new silymarin preparation based on solid dispersion technique. Adv. Ther. 2005, 22, 595-600. [CrossRef] [PubMed]

Sample Availability: Sample of the compound 20(S)-protopanaxadiol is available from the authors.

(C) 2017 by the authors; licensee MDPI, Basel, Switzerland. This article is an open access article distributed under the terms and conditions of the Creative Commons Attribution (CC BY) license (http:/ / creativecommons.org/licenses/by/4.0/). 